\title{
Conventional coronary bypass remains the gold standard reference technique
}

\author{
Khalid $\mathrm{Al}_{e}$ brahim ${ }^{1}$ \\ ${ }^{1}$ King Abdulaziz University Hospital
}

January 31, 2022

\begin{abstract}
anterior mini-thoracotomy in multivessel coronary revascularization by Cyn I read with interest the article, routine minimally invasive approach via left ak and colleagues1. The main problem of mini anterior thoracotomy coronary revascularization is the limited or even bad exposure to the right coronary and posterior obtuse marginal branches which may affect the quality of the distal anastomosis. This is the most important technical point of a successful revascularization.
\end{abstract}

Letter to the editor

Conventional coronary bypass remains the gold standard reference technique

\section{Khaled Ebrahim Al-Ebrahim MBBCh, FRCSC}

Department of surgery, King Abdulaziz University Hospital, King Abdulaziz University Jeddah, Saudi Arabia

Corresponding Author

Khaled Ebrahim Al-Ebrahim, King Abdulaziz University Hospital, Jeddah, Saudi Arabia.

Tel.966 559625170

Email: dr.k.ebrahim@gmail.com

To The Editor

I read with interest the article, routine minimally invasive approach via left anterior mini-thoracotomy in multivessel coronary revascularization by Cynak and colleagues ${ }^{1}$. The main problem of mini anterior thoracotomy coronary revascularization is the limited or even bad exposure to the right coronary and posterior obtuse marginal branches which may affect the quality of the distal anastomosis. This is the most important technical point of a successful revascularization. Good exposure is the cornerstone in any surgical procedure. Surgical stress and learning experience of the surgical team in harvesting the mammary and performing the distal anastomosis through an "unusual " access are also expected obstacles. Full sternotomy and standstill heart provides the best exposure and environment for a high-quality anastomosis with the best flow patency exceeding decades in our literature. Median sternotomy, the most famous heart access, remains relatively painless procedure and its complications are the most preventable in cardiac surgery. Meticticulous surgical technique in opening, sternal respecting closure, preoperative antibiotics and tight glycemic control are the main factors of prevention ${ }^{2}$. Historically, Coronary bypass surgery is the oldest, commonest and most variant procedure in cardiac surgery. Revascularization using cardiopulmonary bypass remains the most popular procedure in practice and resident training programs. This procedure was challenged by several 
modifications in attempt to minimize complications and attract more patients to compete with the interventional cardiologists. These include beating heart, to avoid pump complications, use of radial artery, or total arterial, for better durability, hybrid procedure and recently the use of mini right anterior thoracotomy to avoid sternotomy complications. Robotically assisted HCR requires specialized infrastructure and suites and mainly confined to centers of excellence. Despite all the above advancement in coronary surgery, full sternotomy cardiopulmonary bypass and cardioplegic arrested heart, proved to be the most popular and gold standard reference procedures in daily surgical practice and resident training and competing their results with any other procedure ${ }^{3}$.

\section{References}

1. Çaynak B, Sicim H. Routine minimally invasive approach via left anterior mini-thoracotomy in multivessel coronary revascularization. Journal of Cardiac Surgery,2022

2. .Al-Ebrahim KE, Al-Ebrahim E. Prevention, Classification and Management Review of Deep Sternal Wound Infection. The Heart Surgery Forum 2020 Sep 14 (Vol. 2020, p. 3153.

3. Torregrossa G, Sa MP, Van den Eynde J, Malin JH, Sicouri S, Wertan MC, Ramlawi B, Sutter FP. Hybrid robotic off-pump versus conventional on-pump and off-pump coronary artery bypass graft surgery in women. Journal of Cardiac Surgery. 2022. 